\title{
Music matters: Preattentive musicality of the human brain
}

\author{
STEFAN KOELSCH, ${ }^{\mathrm{a}}$ ERICH SCHROGER, ${ }^{\mathrm{b}}$ AND THOMAS C. GUNTER ${ }^{\mathrm{a}}$

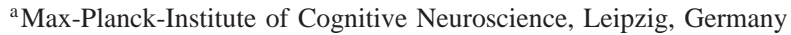 \\ ${ }^{\mathrm{b}}$ University of Leipzig, Leipzig, Germany
}

\begin{abstract}
During listening to a musical piece, unexpected harmonies may evoke brain responses that are reflected electrically as an early right anterior negativity (ERAN) and a late frontal negativity (N5). In the present study we demonstrate that these components of the event-related potential can be evoked preattentively, that is, even when a musical stimulus is ignored. Both ERAN and N5 differed in amplitude as a function of music-theoretical principles. Participants had no special musical expertise; results thus provide evidence for an automatic processing of musical information in "nonmusicians."
\end{abstract}

Descriptors: Electroencephalography, Auditory processing, Music, Early right anterior negativity, N5

In recent studies (Koelsch et al., 2001; Koelsch, Gunter, Friederici, \& Schroger, 2000; Maess, Koelsch, Gunter, \& Friederici, 2001), it was found that within a musical context, harmonically unrelated chords elicit early and late event-related brain potentials (ERPs), termed by the authors the early right anterior negativity (ERAN) and the N5. The term "harmonically unrelated" refers to the fact that, for example, within a C-major context (i.e., within a sequence consisting of chords in C-major) a subsequent $\mathrm{C}$-major chord is harmonically related, whereas a chord from, for example, d-flatmajor is harmonically unrelated (for more detailed descriptions see, e.g., Krumhansl, \& Kessler, 1982; Patel, Gibson, Ratner, Besson, \& Holcomb, 1998; Schönberg, 1969). The ERAN reflected the violation of a musical expectancy and was generated due to an exact representation of the major-minor tonal system in the brains of listeners. The N5 was suggested to reflect processes of harmonic integration. Both ERP components varied in amplitude as a function of the degree of harmonic expectancies induced by a preceding harmonic context. Because participants were nonmusicians, results were suggested to indicate an implicit musicality of the human brain.

The aim of the present study was to investigate whether ERAN and N5 can be elicited preattentively, that is, whether listeners use their (implicit) musicality to musical stimuli also under a condition in which these stimuli are ignored. The employed stimuli were very similar to those used in previous studies (Koelsch, Gunter, et al., 2000, 2001; Maess et al., 2001). Stimuli were chord sequences, each sequence consisting of five chords (Figure 1a). The sequences were presented one directly following the other, in the form of a musical piece. They consisted mainly of in-key chords,

The present project has generously been supported by Marantz. Examples of stimuli and full color potential maps can be found at http://www. stefan-koelsch.de.

Address reprint requests to: Stefan Koelsch, Max-Planck-Institute of Cognitive Neuroscience, Stephanstrasse 1a D-04103 Leipzig, Germany. E-mail: mail@stefan-koelsch.de. but infrequently, either the third or the fifth chord was a "Neapolitan sixth chord" (Figure 1b,c; Neapolitan chords were invented in Naples in the 17th century and have since then become a popular stylistic element in western tonal music). Neapolitan chords are harmonically only distantly related to the preceding chords and hence assumed to be perceived as unexpected, at least when attended (Bharucha \& Krumhans1, 1983; Bharucha \& Stoeckig, 1986, 1987; Krumhansl \& Kessler, 1982). Such a violation of harmonic expectancy is predicted to elicit an ERAN. It is important to note that it is only the relation to a preceding musical context that makes a Neapolitan chord sound unexpected, a Neapolitan chord itself is a (perfectly normal sounding) major triad.

From a music-theoretical perspective, chord sequences consisting only of in-key chords (in musical terms cadences) were arranged in a way that a musical context was built up towards the end of each cadence. That is, the home key of a cadence was clearly established with progressing in-key chords. For example: when the first chord of a cadence was $c-e-g$, and the second chord $f-a-c$, several home keys were possible, because both chords belong to keys like C-major, F-major, or a-minor. In contrast, after four in-key chords, a single key was unequivocally established (for a more detailed description see, e.g., Krumhansl \& Kessler, 1982).

Several behavioral studies have shown that the build-up of musical context is psychologically represented in music listeners as the establishment of a "hierarchy of harmonic stability" (Bharucha \& Krumhansl, 1983; Bharucha \& Stoeckig, 1986; Krumhansl \& Kessler, 1982). Basically, this hierarchy implies a notion of the home key, and specifies the degree of musical expectancies for certain (e.g., harmonically related) chords to follow.

In the present study, the Neapolitan chords (in C-major: a flat / d flat / $f$, infrequently occurring at the third and/or fifth position of a cadence) contained notes that were harmonically only weakly related to the preceding musical context. According to the represented hierarchy of stability, such chords are perceived as unexpected (e.g., Bharucha \& Krumhansl, 1983; Krumhansl \& Kessler, 1982). 
(a)
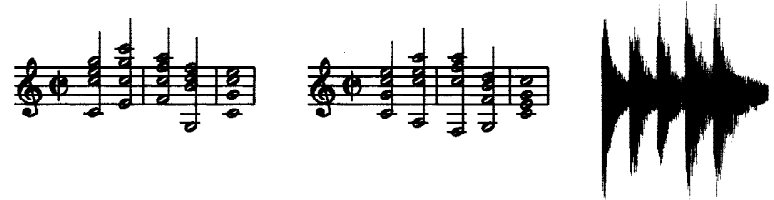

(b)
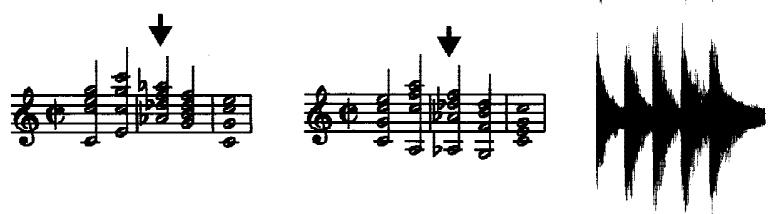

(c)

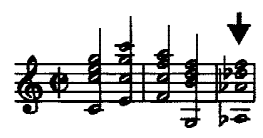

$3.6 \mathrm{~s}$

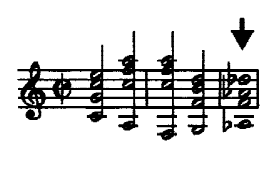

$3.6 \mathrm{~s}$

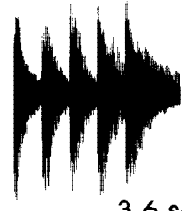

$3.6 \mathrm{~s}$

Figure 1. Left: Example of two chord sequences exclusively consisting of in-key chords (a), containing a Neapolitan sixth chord at the third (b) and at the fifth positions (c). Neapolitan chords are indicated by arrows. Right: Amplitude waveforms of examples of auditory stimuli. Each sequence had a duration of $3.6 \mathrm{~s}$ (presentation time of chords 1-4: $600 \mathrm{~ms}$, of chord 5: $1,200 \mathrm{~ms})$. Neapolitan and in-key chords were on average physically matched with respect to their frequencies and loudness.

Moreover, if participants are sensitive to a musical context build-up (entailing the establishment of a harmonic hierarchy of stability), the harmonic expectancies of the participants should be more specific at the fifth compared to the third position of a cadence. Thus, Neapolitan chords were hypothesized to violate the harmonic expectancies of listeners to a higher degree when presented at the fifth position than when presented at the third position (indicated in an enhancement of both ERAN and N5).

In a first experimental block, the cadences were presented to the participants (all nonmusicians; see Methods) under the instruction to ignore the music and to read a self-brought book (a procedure commonly employed to investigate auditory processing in the absence of attention; e.g., Näätänen, 1992; Schroger, 1998). During the experimental session, the EEG was recorded. ERPs were calculated off-line from the EEG. To investigate effects of attention on the ERPs, a second block was performed, in which participants were informed about the presence of Neapolitan chords, asked to detect the Neapolitans, and indicate their detection by pressing a response button.

\section{Methods}

\section{Participants}

Eighteen nonmusicians (aged 18 to 27 years, mean 23.4 years; 9 women) participated in the experiment. No participant played an instrument or had any singing lessons; no participant had any musical education or musical expertise besides normal school education. All subjects were right-handed and reported themselves to have normal hearing.

\section{Stimuli}

All chords consisted of synthesized piano sounds played under computerized control via MIDI on a Roland JV-2080 synthesizer. Chord sequences were randomly chosen from a pool of 108 dif- ferent chord sequences. Twenty percent of all sequences contained a Neapolitan chord at the third position and $20 \%$ contained a Neapolitan at the fifth position. Seven hundred fifty chord sequences were presented in the first block ( 150 sequences contained a Neapolitan at the third position and 150 a Neapolitan at the fifth position), 250 in the second block (50 Neapolitans occurred at the third position and 50 Neapolitans at the fifth position).

Chord sequences consisted of five chords each. Duration of chords 1-4 was $600 \mathrm{~ms}$, that of the fifth chord 1,200 ms. All chords had the same loudness and the same decay of loudness (cf. Figure 1). There was no silent period between chords or chord sequences; one chord sequence directly succeeded the other. Both Neapolitans at the third and at the fifth position were physically identical (within the first $600 \mathrm{~ms}$ ). All sequences began with a tonic chord. Chords at the second position were tonic, subdominant, mediant, or submediant; at the third position: subdominant, Neapolitan chord, dominant, or dominant six-four chord; at the fourth position: dominant seventh chord; at the fifth position: tonic or Neapolitan chord. All chords were presented in different voicings (e.g., with the root, the third, the fifth, and the seventh in the soprano-voice, i.e., in the top voice), leading to the pool of 108 different chord sequences. Chords were played with approximately $55 \mathrm{~dB}$ SPL. Chord sequences containing a Neapolitan chord were always preceded by a cadence exclusively consisting of in-key chords. Part writing was according to the classical rules of harmony (e.g., Hindemith, 1940).

\section{Procedure}

Participants were seated in a comfortable chair in an electrically and acoustically shielded room. In the first block, subjects read a self-brought book under the instruction to ignore all acoustic stimuli. Block duration was $45 \mathrm{~min}$. In the second block, participants were asked to respond to the Neapolitan chords by pressing a button. Duration of the second block was 14 min.

\section{EEG Measurements}

The EEG was recorded from 29 scalp sites of the 10-20 system (Nz, FP1, FP2, AF7, AF8, F7, F3, Fz, F4, F8, FT7, FC3, FC4, FT8, T7, C3, Cz, C4, T8, CP5, CP6, A2, P7, P3, Pz, P4, P8, O1, $\mathrm{O} 2$ ). The reference was the left mastoid (A1). Sampling rate was $250 \mathrm{~Hz}$ (lowpass $40 \mathrm{~Hz}$ ). The horizontal EOG was recorded bipolarly between electrodes situated at the outer right and outer left canthi. The vertical EOG was recorded bipolarly between electrodes situated above and below the right eye. To guarantee that the evaluated stimuli were not attended by the participants in the first block, only epochs with horizontal eye movement (indicating the reading of participants) were included in the data analysis of the first block.

\section{Data Analysis}

For elimination of artifacts caused by drifts or body movements, EEG data of both blocks were rejected off-line from the raw EEG whenever the standard deviation within any 500-ms interval of all data exceeded $20 \mathrm{mV}$ at all electrodes.

For elimination of artifacts caused by eye movements in the first block, EEG data were rejected off-line from the raw EEG whenever the standard deviation within any 200-ms interval of all data exceeded $40 \mathrm{mV}$ at the vertical EOG. Epochs with no [sic] horizontal eye movement were rejected off-line from the raw EEG. That is, only epochs with horizontal eye movements (indicating the reading of participants) were included in further data analysis. 
For elimination of artifacts caused by eye movements in the second block, EEG data were rejected off-line from the raw EEG whenever the standard deviation within any 200-ms interval of all data exceeded $20 \mathrm{mV}$ at either the horizontal or the vertical EOG. Rejections of all data were visually controlled by the first author. After the rejection procedures, EEG data were referenced off-line to the algebraical mean of both mastoid electrodes.

For statistical evaluation, ERPs were analyzed by repeated measures analyses of variance as univariate tests of hypotheses for within-subjects effects. To test the distribution of effects, four regions of interest (ROIs) were computed for statistical evaluation: left anterior (mean of F3, FC3, and C3), right anterior (mean of F4, FC4, and C4), left posterior (mean of P3, CP5, O1), and right posterior (mean of $\mathrm{P} 4, \mathrm{CP} 6, \mathrm{O} 2$ ). ANOVAs were conducted with factors chord type (in-key chords vs. Neapolitans), position (chords at the third vs. chords at the fifth position of the chord sequences), hemisphere (left vs. right ROIs), and anterior-posterior distribution (anterior vs. posterior ROIs). Chords at the fifth position of the cadence were not included in the data analysis when they occurred after a Neapolitan chord at the third position. ERPs presented in figures were for presentation purposes $10-\mathrm{Hz}$ low-pass filtered (41 points, finite impulse response). ERPs presented as potential maps were referenced off-line to the nose electrode.

\section{Results}

\section{Block 1, Neapolitans}

ERPs of expected in-key chords opposed to Neapolitan chords are shown in Figures 2-4. When presented at the fifth position of a chord sequence, Neapolitan chords elicited a distinct early negative potential (around 150-250 ms) that was right anteriorly predominant, the early right-anterior negativity, or ERAN (Figure 2).
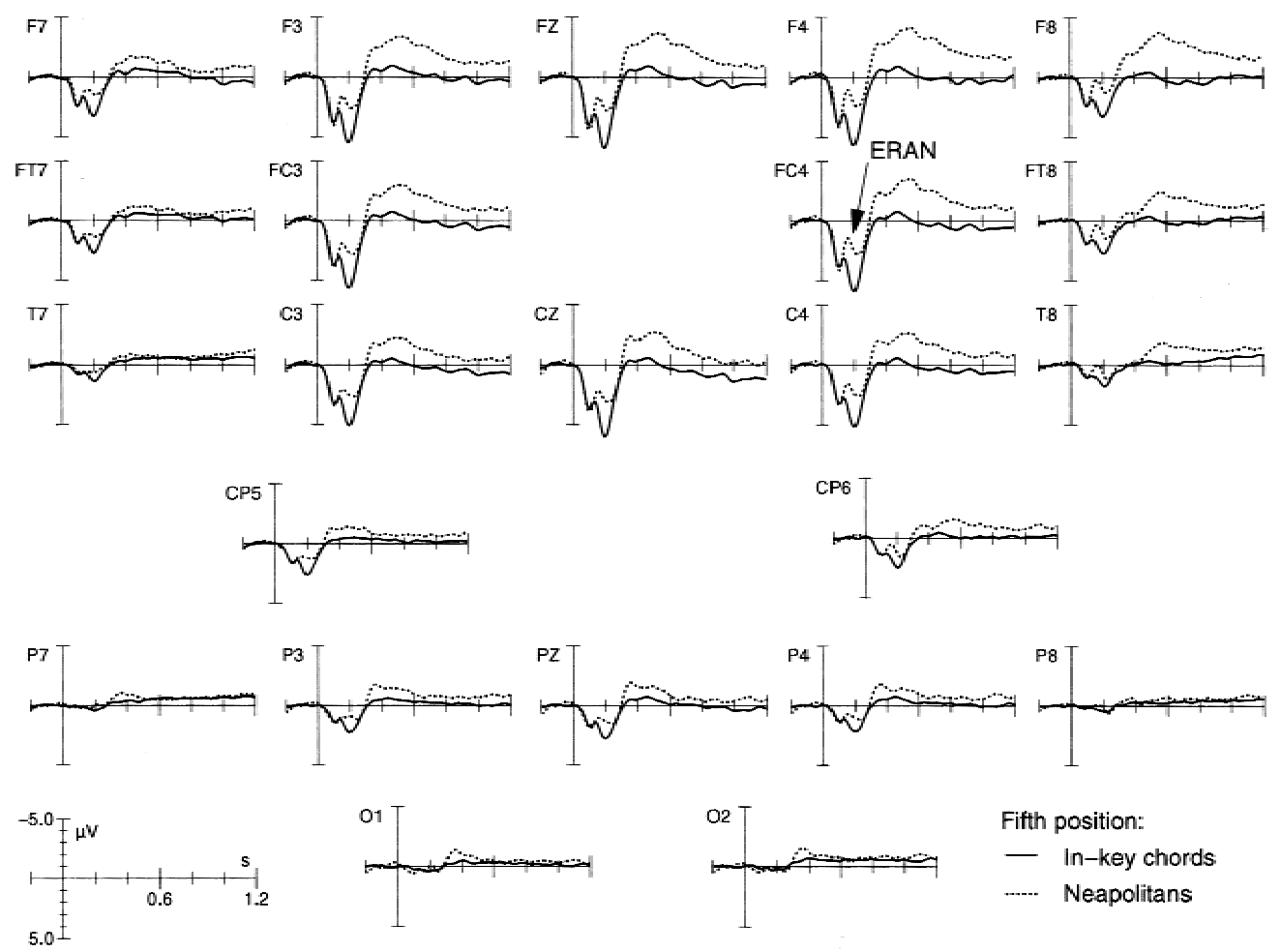

Fifth position:

- In-key chords

Neapolitans
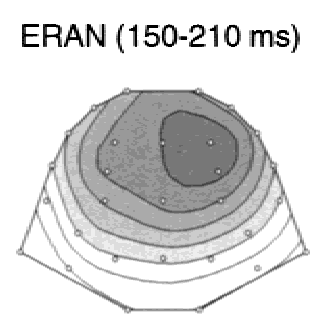

N5 (400-600 ms)
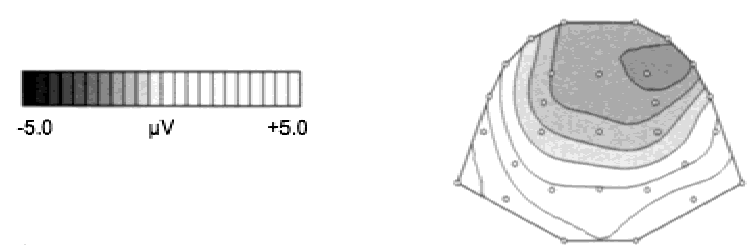

Figure 2. First block, ERPs to chords at the fifth position. Top: ERP waveforms; Neapolitan chords elicited an early right-anterior negativity (ERAN, maximal around $150-250 \mathrm{~ms}$ ), and a late negativity (N5, around 400-600 ms). Reference is the mean of A1 and A2. Bottom: Scalp distribution of effects elicited by Neapolitan chords at the fifth position (potential maps of difference ERPs: in-key chords subtracted from Neapolitan chords) for an early (150-210 ms, left) and a late (400-600 ms, right) time interval, with nose reference; white areas indicate positive potentials. When nose reference is used, both ERAN and N5 invert polarity at centrotemporal electrodes. 

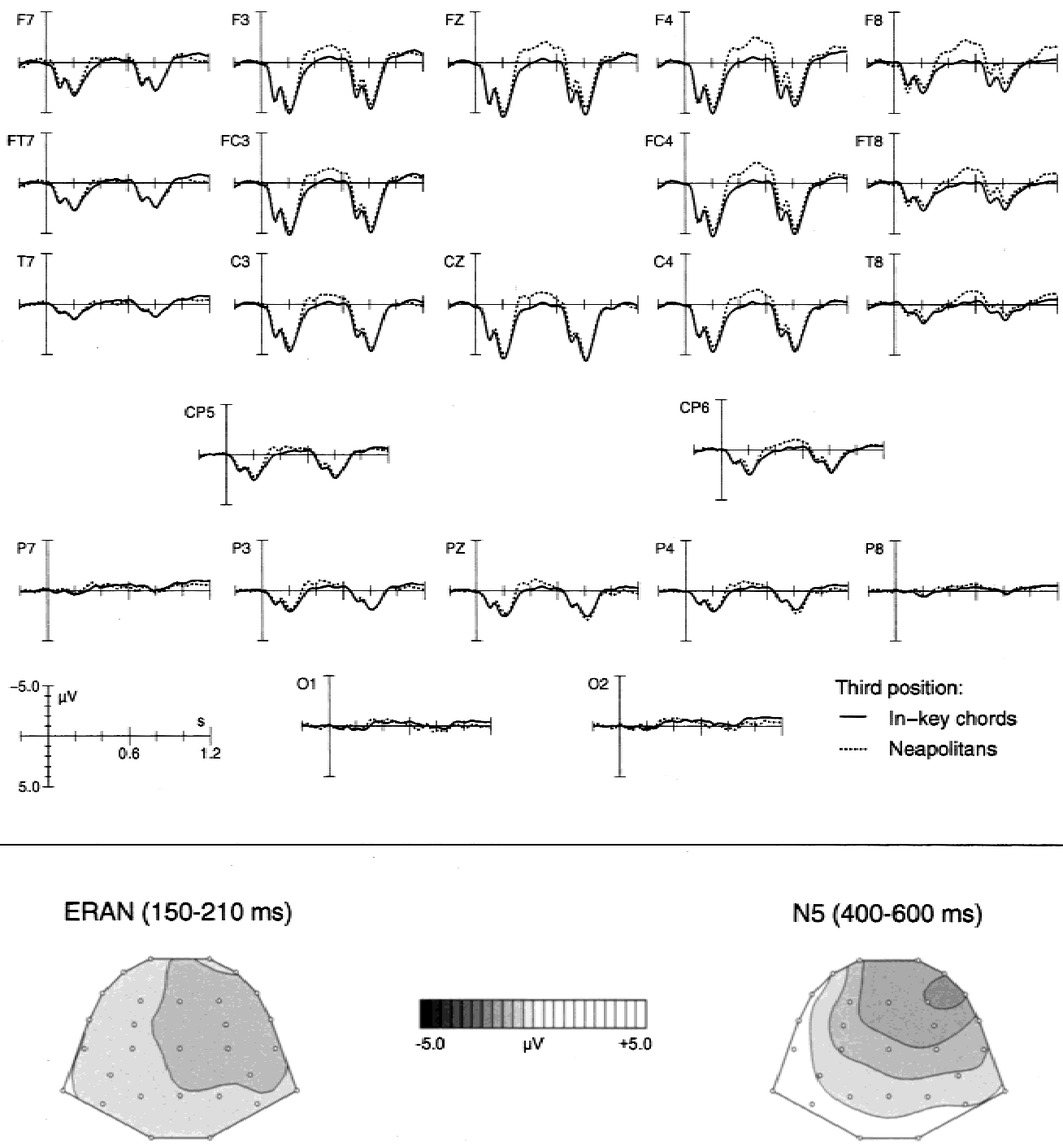

Figure 3. First block, ERPs to chords at the third position. Top: ERP-waveforms; Neapolitan chords elicited only a small ERAN, and a distinct N5. Bottom: Scalp distribution of effects elicited by Neapolitan chords at the third position (potential maps of difference ERPs: in-key chords subtracted from Neapolitan chords, with nose reference; white areas indicate positive potentials) for an early $(150-210 \mathrm{~ms}$, left) and a late $(400-600 \mathrm{~ms}$, right) time interval.

The ERAN was maximal around $185 \mathrm{~ms}$. When referenced to the mean of both mastoids (as shown in the top of Figure 2), Neapolitans elicited more negative ERPs at all scalp sites. With a nosetip reference (shown in the bottom part of Figure 2), the ERAN is negative over the front half of the head, but inverts polarity more posteriorly. From centrotemporal sites posterior (including the mastoids), the ERAN is positive-going with this reference (Figure 2, bottom left). Neapolitans at the third position elicited only a very small ERAN (n.s.; Figure 3). Both Neapolitans at the third and at the fifth positions elicited a right-frontally distributed negativity, which was maximal around 500-600 ms. This effect becomes significant around $380 \mathrm{~ms}$ and has its maximal peak amplitude between 500 and $550 \mathrm{~ms}$. A labeling of this effect could be "N550"; as a working term, however, this effect is termed here, as in previous studies (Koelsch, Gunter, et al., 2000; Koelsch et al., 2001), the "N5." The N5 was considerably larger in amplitude when elicited at the fifth position compared to when elicited at the third position (Figure 4). Notably, no Neapolitans at the third and fifth positions elicit $\mathrm{N} 2 \mathrm{~b}$, or a P3a or P3b component. Similarly to the ERAN, the N5 inverted polarity at centrotemporal scalp regions when nose reference is used (bottom right of Figures 2 and 3).

An ANOVA for an early time interval (150-210 ms), using factors chord type (in-key chords vs. Neapolitan chords) and position (third vs. fifth) revealed an effect of chord type, $F(1,16)=$ 22.22, $p<.0002$, and an interaction between the two factors, $F(1,16)=15.58, p<.002$. An ANOVA for the same time interval, conducted for chords at the third position only, using factors chord type, hemisphere, and anterior-posterior distribution, did not yield an effect of chord type, whereas the analogous ANOVA for chords at the fifth position did reveal an effect of chord type, $F(1,16)=$ 32.06, $p<.0001$, a clear interaction between factors chord type and anterior-posterior distribution, $F(1,16)=41.07, p<.0001$, and a marginal interaction between factors chord type and hemisphere, $F(1,16)=3.52, p<.08$. An ANOVA for the chords at the fifth position with factors chord type and hemisphere conducted 

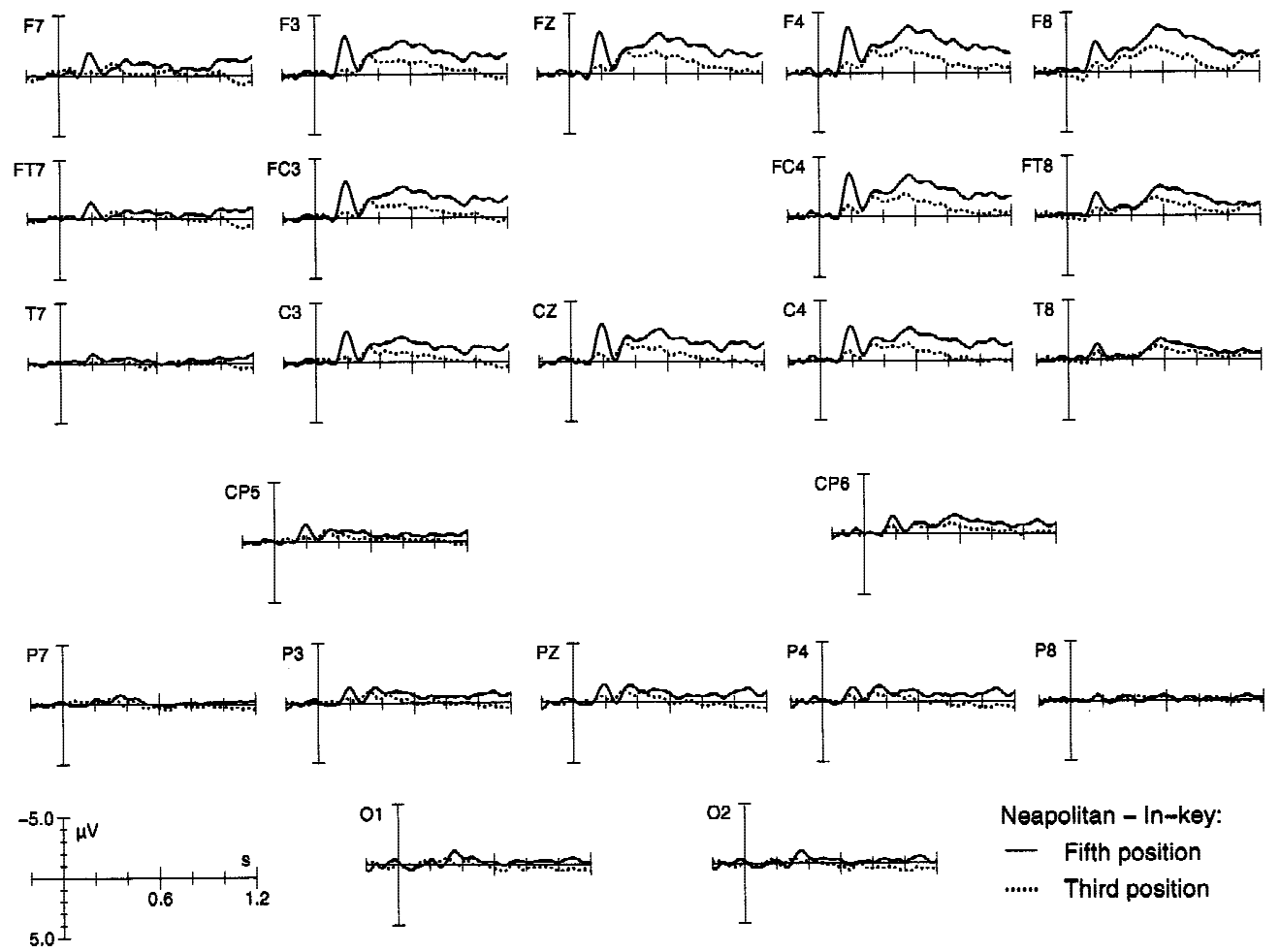

Figure 4. First block, third verssus fifth position, difference ERPs (in-key chords subtracted from Neapolitan chords). Both ERAN and N5 were considerably smaller at the third compared to when elicited at the fifth position, indicating that chords were processed dependent of the preceding musical context.

for the frontal ROIs revealed an effect of chord type, $F(1,16)=$ $42.38, p<.0001$, and an interaction between the two factors, $F(1,16)=5.26, p>.9$.

An ANOVA for a late time interval (400-600 ms), using factors chord type, position, hemisphere, and anterior-posterior distribution revealed an effect of chord type, $F(1,16)=18.85, p<$ .0005 , an interaction between factors chord type and position, $F(1,16)=11.09, p<.005$, an interaction between factors chord type and hemisphere, $F(1,16)=5.33, p<.05$, an interaction between factors chord type and anterior-posterior, $F(1,16)=36.05$, $p<.0001$, an interaction between factors chord type, hemisphere, and anterior-posterior, $F(1,16)=4.68, p<.05$, and no interaction between factors chord type, position, hemisphere, and anteriorposterior, $F(1,16)=0.01, p>.9$.

\section{Block 1, Split-Half}

In contrast to previous experiments (Koelsch, Gunter, et al., 2000), the N5 elicited by the Neapolitans was right-lateralized. In the previous experiments, however, the experimental block was less than half as long as in the present experiment. To investigate whether the N5 elicited by Neapolitans altered during the first block, the collected trials were divided in halves and compared against each other (the first $50 \%$ of the trials versus the second $50 \%$ ). Data of the chords at the fifth position are shown in Figure 5. Within the first half of the first block, the N5 elicited by Neapolitans was bilateral, whereas the N5 was lateralized when elicited in the second half.

An ANOVA (400-600-ms time window) with factors chord type, half (first versus second), and ROI (employing all four regions) yielded an interaction between the three factors, $F(1,16)=$ $3.85, p<.02$, indicating that the effects elicited by the incongru- ous chords had a different scalp distribution in the two halves of the first block. Neapolitans at the third position showed a similar trend, which was, however, statistically not significant. No difference between the two halves was found for the ERAN or for ERPs elicited by in-key chords.

\section{Block 2, Behavioral Data}

Participants detected more Neapolitans at the fifth position (97\%) compared to the third position $(74 \%)$. Similarly, false-alarm rates

\section{N5 (400-600 ms)}

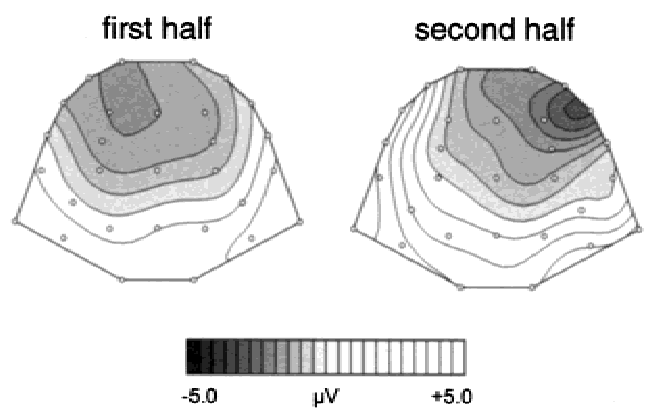

Figure 5. First block, split half. During the first half of the block, the N5 elicited at the fifth position had a bilateral scalp distribution (left), whereas the N5 was lateralized to the right during the second half (right). Potential maps (with nose reference; white areas indicate positive potentials) were calculated by subtracting ERPs of in-key from Neapolitan chords; ERPs were interpolated over a time window from 400 to $600 \mathrm{~ms}$. 
were higher for responses at the third (participants responded on average to $2 \%$ of all in-key chords) compared to the fifth position $(0.45 \%)$. Reaction times were only slightly (n.s.) faster for Neapolitan chords at the fifth $(567 \mathrm{~ms})$ compared to the third position (596 ms).

An ANOVA of hit percentages at the fifth versus third position revealed an effect of position, $F(1,17)=28.7, p<.0001$. An ANOVA of false-alarm percentages at the fifth versus third position also revealed an effect of position, $F(1,17)=7.77, p<.05$.

\section{Block 2, ERPs}

Brain responses of the second block are shown in Figures 6-8. Just as in the first block, Neapolitan chords at the fifth position of the chord sequence elicited a distinct ERAN (Figure 6). Neapolitans at the third position elicited only a small ERAN (n.s., Figures 7 and 8). The ERAN elicited at the fifth position was followed by an N2b-P3-complex reflecting the conscious detection of Neapolitan chords and the decisional processes preceding the button-press responses (Näätänen, 1992; Pritchard, 1981; Schröger, 1998). As with Neapolitans at the fifth position, Neapolitans at the third position elicited a P3. Contrary to the first block, no N5 is visible in the ERPs of Neapolitan chords at the fifth position, most presumably due to the overlap of a large P3 component. At the third position, where fewer Neapolitan chords were detected (and the P3 is smaller compared to the fifth position), an N5 is still slightly visible at frontal sites, but not statistically significant.

An ANOVA for the early interval from 150 to $210 \mathrm{~ms}$ with factors chord type (in-key vs. Neapolitan chord) and position (third vs. fifth) revealed an effect of condition, $F(1,16)=24.18, p<$ .0002 , and an interaction between the factors, $F(1,16)=22.38$, $p<.0002$. An ANOVA for the same time interval for chords at the third position only, with factors chord type, hemisphere, and anterior-posterior distribution, did not yield an effect of chord type, whereas the analogous ANOVA for chords at the fifth position revealed an effect of chord type, $F(1,16)=37.01, p<.0001$, an interaction between factors chord type and anterior-posterior distribution, $F(1,16)=79.77, p<.0001$, and an interaction between factors chord type and hemisphere, $F(1,16)=8.18, p<.02$.

Early differences between Neapolitans and in-key chords (150$210 \mathrm{~ms}$ ) at the third position were not significant when analyzing the data for Blocks 1 and 2 separately. However, when the data of both blocks were pooled (resulting in a better signal-to-noise ratio), an ANOVA with factors block (1 vs. 2), chord type, hemisphere, and anterior-posterior distribution revealed a marginal effect of chord type, $F(1,34)=3.21, p<.08$, a marginal interaction between factors chord type and anterior-posterior distribution, $\mathrm{F}(1,34)=3.29, p<.08$, and an interaction between factors chord type and hemisphere, $F(1,34)=5.99, p<.02$. When conducting the analogous ANOVA for the frontal ROIs only, an effect of chord type was revealed, $F(1,34)=4.27, p<.05$.

\section{Block 1 Versus 2, In-Key Chords}

The N1 elicited by in-key chords distinctly differed between the unattended and the attended condition (cf. Figure 9). The difference between the brain responses was maximal around $130 \mathrm{~ms}$ and largest over frontocentral scalp regions. An ANOVA analyzing a time interval from 80 to $150 \mathrm{~ms}$, conducted for the in-key chords from positions 3 and 5 with factors attention (ignore vs. attend) and position revealed an effect of attention, $F(1,34)=7.94, p<$ .008 .

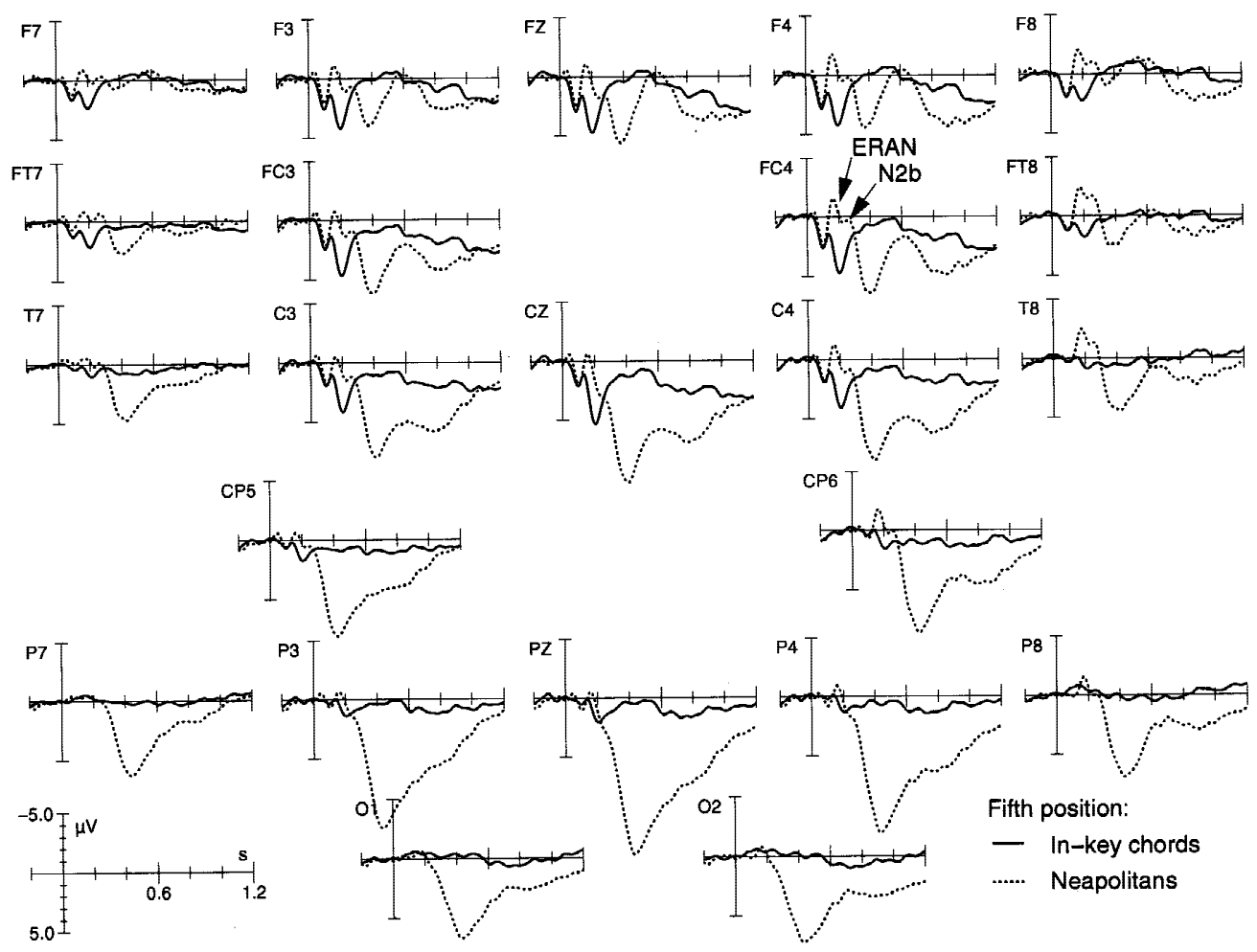

Figure 6. Second block (attend condition), ERPs to chords at the fifth position. Neapolitan chords elicited an ERAN and a subsequent N2b-P3-complex; an N5 is presumably compensated by the positive potentials of the P3. 

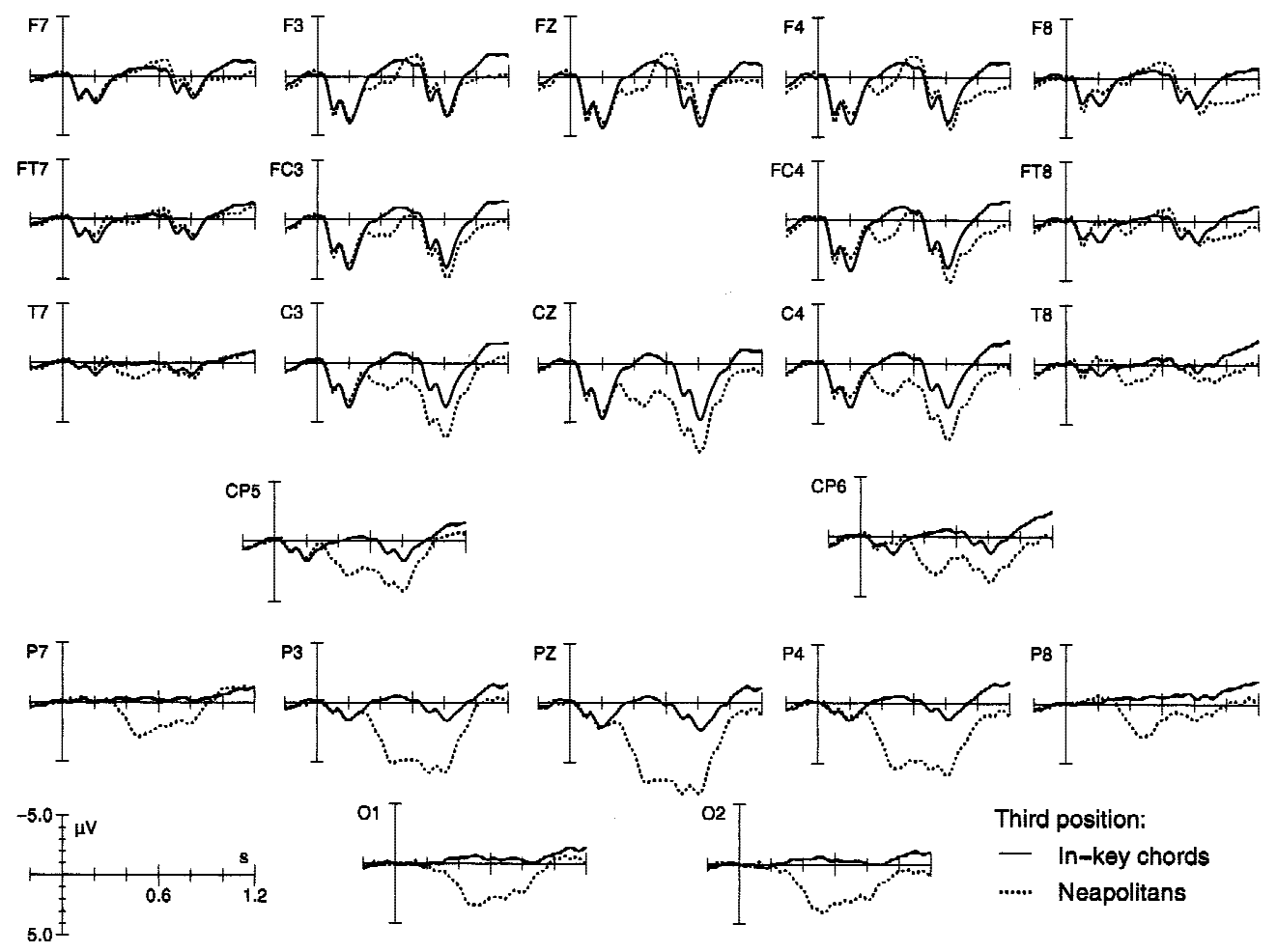

Third position:

- In-key chords

...... Neapolitans

Figure 7. Second block, ERPs to chords at the third position. Neapolitan chords elicited only small ERAN and N5 (both n.s.), and a distinct P3.

\section{Block 1 Versus 2, Neapolitans}

The ERAN elicited by Neapolitans barely differed between blocks (Figure 10). An ANOVA for the early interval from 150 to $210 \mathrm{~ms}$ with factors block, chord type, position, hemisphere, and anteriorposterior distribution revealed an effect of chord type, $F(1,34)=$ $46.13, p<.0001$, an interaction between factors chord type and position, $F(1,34)=37.29, p<.0001$, an interaction between factors chord type and hemisphere, $F(1,34)=15.83, p<.0005$, an interaction between factors chord type and anterior-posterior distribution, $F(1,34)=80.69, p<.0001$, but no interaction between factors chord type and block, $F(1,34)=0.26, p>.6$.

\section{ERAN (150-210 ms)}

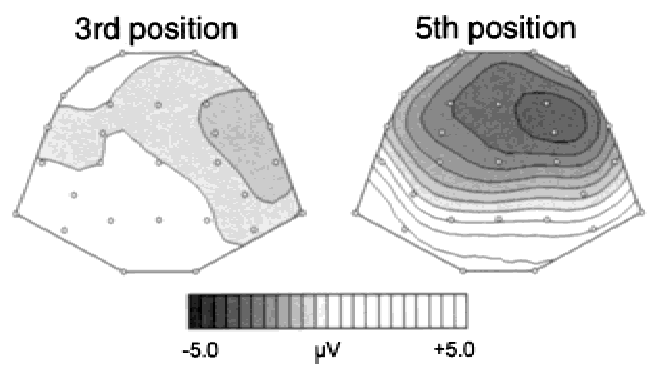

Figure 8. Second block, potential maps of the ERAN elicited by Neapolitan chords at the third (left) and fifth (right) positions (difference ERPs: in-key chords subtracted from Neapolitan chords, interpolated over the time interval from 150 to $210 \mathrm{~ms}$, with nose-reference; white areas indicate positive potentials). As in the first block, the ERAN is distinctly larger when elicited at the fifth position.
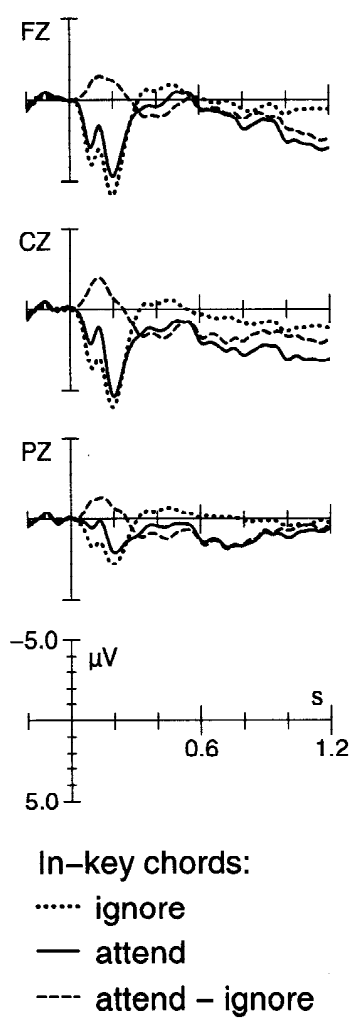

Figure 9. Block 1 versus 2, in-key chords from fifth position. The N1 is distinctly larger in the second block, reflecting that participants attended the stimuli during the second block (dashed line indicates the difference wave: ERPs from the first subtracted from second block). 

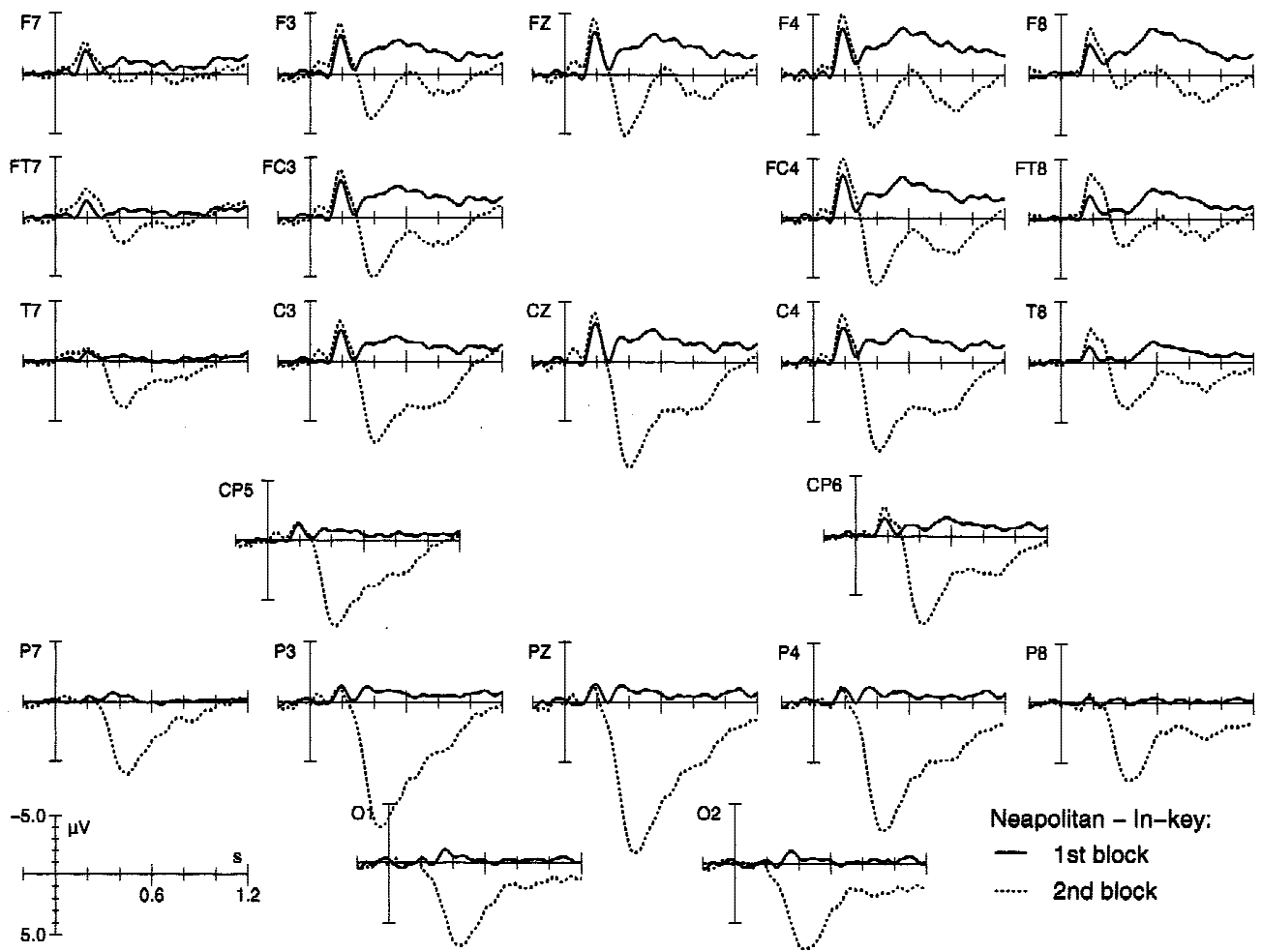

Figure 10. Block 1 versus 2, effects elicited at the fifth position (difference waves: in-key subtracted from Neapolitan chords). The amplitude of the ERAN does not significantly differ between both blocks, suggesting that the processes underlying the generation of the ERAN are fairly independent of attention.

\section{Discussion}

ERPs of Neapolitans distinctly differed from ERPs elicited by in-key chords. Neapolitan chords of Block 1 elicited an early right anterior negativity (maximal around $200 \mathrm{~ms}$ ) and a late negativity with an onset around $380 \mathrm{~ms}$ that peaked around $500-550 \mathrm{~ms}$ (labeled, as a working term, the N5). It is important to note that a Neapolitan chord itself is a perfectly common major triad-it is only the preceding harmonic context that makes it sound peculiar (at least for listeners familiar with the major-minor tonal system). That is, a Neapolitan can only be recognized as incongruous by the application of (implicit) knowledge about the principles of harmonic distance and relatedness that constitute the major-minor tonal system.

Notably, both ERAN and N5 were present, though participants were instructed to ignore the musical stimulus. Several ERP indices give evidence that the stimuli were actually ignored: First, no $\mathrm{N} 2 \mathrm{~b}$, no P3a, and no P3b were elicited by Neapolitans, showing that the Neapolitans were not attended and detected (cf., e.g., Näätänen, 1992; Pritchard, 1981). Second, the N1 was clearly larger when elicited in the second (attend) block compared to the ignore condition; the $\mathrm{N} 1$ is known to be larger when subjects attend the stimuli than when ignoring them (e.g., Näätänen \& Picton, 1987). Moreover, only epochs with horizontal eye movements (indicating the reading of participants) were included in the data evaluation. The present results thus show that both ERAN and N5 can be elicited preattentively, that is, even when a musical stimulus is ignored.

The ERAN is taken to reflect the violation of listeners' musical expectancy (Koelsch, Gunter, et al., 2000): Neapolitan chords were harmonically incongruous, as they were tonally only distantly related to the preceding musical context. Harmonically incongruous chords have under attend conditions in behavioral experiments been shown to be perceived as unexpected (e.g., Bharucha \& Krumhansl, 1983; Bharucha \& Stoeckig, 1986; Krumhansl \& Kessler, 1982; Bigand \& Pineau, 1997). This interpretation of the ERAN suggests that musical expectancies can be established and violated preattentively.

The ability of the human brain to process harmonic relations (which can be described by music theory) and to expect musical events to a greater or lesser degree may be taken as psychological reality of a "musical syntax" (Swain, 1997). Moreover, Neapolitan chords are, as chord functions within a rule-based harmonic context, "music-syntactically" considerably less inappropriate at the third position of the sequences compared to the fifth position: At the third position, a Neapolitan functions as a subdominant-substitute and predominant chord, which can thus relatively easily be assimilated in the surrounding musical context. At the fifth position, only a (concluding) tonic chord was to be expected; thus Neapolitans were highly inappropriate. Note that the present interpretation of the ERAN reflecting music-syntactic processing is consistent with findings of a previous magneto-encephalographic (MEG) study from Maess et al. (2001; see also Koelsch, Maess, \& Friederici, 2000). In that study an experimental protocol very similar to that of the present study was used. The neuronal generators of the ERAN were localized in Broca's area and its right-hemisphere homologue (BA 44), areas known to be involved in syntactic language processing (Dapretto \& Bookheimer, 1999; Friederici, Wang, Herrmann, Maess, \& Oertel, 2000; Just, Carpenter, Keller, Eddy, \& Thulborn, 1996; Meyer, Friederici, \& von Cramon, 2000). 
The N5 is suggested to reflect processes of harmonic integration, entailing a modification of listeners' hierarchy of harmonic stability. Neapolitan chords were harmonically only distantly related, which made the integration of Neapolitans into the musical context more difficult. Moreover, the hierarchy of stability was presumably modified towards a new tonal center that is more compatible with both the expected in-key and the unexpected Neapolitan chords.

Interestingly, the N5 is reminiscent of the N400 elicited by semantically incongruous words in a sentence (Kutas \& Hillyard, 1980). However, though the N5 was bilateral during the first half of the first block, it was lateralized to the right during the second half. This contrasts with the N400, which has so far not been reported to alter its scalp distribution. The shift of the distribution of the N5 in the present experiment may be due to an habituation of the brain system responsible for the processing of Neapolitan chords: As the system had "recognized" that the unexpected chords were always Neapolitan chords, the right hemisphere might have been sufficient to integrate these chords.

Notably, the N5 but not the ERAN alters its scalp distribution during the first block, supporting the hypothesis that ERAN and N5 are two separate ERP components, rather than merely a slow negative shift (see also Koelsch, Gunter, et al., 2000). Thus, the ERAN is not a short modulation of a longer, larger, and equally widely distributed negative shift, but rather a separate potential with a right-anterior maximum.

The hypotheses about ERAN and N5 are supported when comparing the data from the third and fifth positions of the chord sequences: Both ERAN and N5 were distinctly larger when elicited at the fifth compared to the third position. This amplitude difference could not be due to any physical difference between Neapolitan chords at the third and fifth positions (see Methods). It is suggested that the amplitude difference is a function of the harmonic expectancies of listeners. These expectancies were induced by the preceding harmonic context, and more specific at the fifth compared to the third position of the sequences. The expectancies were determined by the context build-up towards the end of each chord sequence (entailing a more specified hierarchy of stability), by the occurrence of a dominant-seventh chord at the fourth position (which induces a strong expectation for a tonic chord), and by the nature of a Neapolitan chord at the third position as a predominant chord (which can be assimilated into the larger harmonic context). The greater violation of musical expectancy corresponds to the larger amplitude of the ERAN when elicited at the fifth position. Because the musical context was specified to a higher degree at the fifth compared to the third position, Neapolitan chords at the fifth position also required more modification of the hierarchy of tonal stability (i.e., more effort of integration into the preceding musical context), resulting in a larger N5.

It is important to note that the differing degree of harmonic expectancy (as reflected in the different ERPs of in-key and $\mathrm{Ne}$ apolitan chords, as well as in the larger effects elicited by Neapolitans at the fifth vs. the third position) follows the principles of music theory. With this respect, the brain responses of participants differed musically in amplitude, according to a preceding harmonic context. Given the fact that participants were nonmusicians, the present results hence provide evidence for a preattentive musicality of the human brain.

The behavioral results of the second block indicate that Neapolitan chords were more salient at the fifth than at the third position of the chord sequences, supporting the hypotheses about the influence of musical context build-up on musical processing. Besides, the ERAN seems to be only marginally influenced by attention, strengthening the hypothesis that the cognitive processes underlying the generation of the ERAN are at least partly automatic (and can thus be elicited preattentively). The N5 was, due to compensation by the huge P3, not significant when compared with the ERPs of in-key chords (where, naturally, no P3 was present). However, when looking at the ERP waveforms of Neapolitan chords, especially at those from the fifth position, an N5 is clearly visible at mediofrontal electrodes in the time interval between 500-600 ms. Because the N5 is present under a condition where Neapolitan chords are attended but not task-relevant (Koelsch, Gunter, et al., 2000), it is highly probable that, though over the scalp overlapped by the P3, an N5 was elicited by Neapolitan chords in the second block.

\section{ERAN and N1}

Several indices prove that the ERAN is not an enhanced N1. First, the $\mathrm{N} 1$ is generated (at least to a considerable degree) in the temporal lobe, whereas the ERAN receives its main contributions from an area in the frontal lobe (Maess et al., 2001; see above). Second, the ERAN is, in contrast to the N1, elicited by the application of (implicit) knowledge of harmonic relatedness (note that in the present experiment, in-key and Neapolitan chords at the third and fifth positions were physically identical). Third, whereas the N1 is clearly larger in the attend compared to the ignore block, the amplitude of the ERAN virtually does not differ between blocks.

\section{ERAN and RATN}

The functional significance of both ERAN and right anteriotemporal negativity (RATN; Patel et al., 1998) seems to be somewhat similar, as the RATN was also taken to reflect a music-specific application of syntactic rules. However, the latency of the RATN is distinctly longer that that of the ERAN (the RATN is maximal around $350 \mathrm{~ms}$ ), and, in contrast to the ERAN, only visible over the right hemisphere (the RATN is hardly visible even over midline leads). Moreover, the RATN has so far only been reported to be elicited in musicians. Therefore, we prefer, for the time being, the term ERAN for the effects described in the present study.

\section{ERAN and MMN}

The ERAN shows some similarities to the mismatch negativity (MMN; Näätänen, 1992; Schroger, 1998). Most obviously, both ERAN and MMN are frontally distributed negativities evoked around 100-200 ms by deviant stimuli. However, there are also some important differences between the two components. First, a recent study from Koelsch, Gunter, et al. (2001) revealed that in contrast to the ERAN (which is due to the musical context considerably larger at the fifth than at the third position), both frequency MMN and abstract-feature MMN do not show differences in amplitude between third and fifth positions of a stimulus sequence when presented in a paradigm analogous to that of the present study. Second, the ERAN is, as noted before, generated in the inferior frontolateral cortex (Maess et al., 2001), whereas the main generators of the MMN are located in temporal regions within or in the close vicinity of primary auditory cortex (though additional contributions to the MMN have been reported for dorsolateral prefrontal cortex; see Alain, Woods, \& Knight, 1998; see also Giard, Perrin, Pernier, \& Bouchet, 1990; Opitz, Mecklinger, von Cramon, \& Kruggel, 1999). Note that the polarity inversion of the ERAN (when nose reference is used) is distinctly more anterior 
compared to the MMN (bottom right of Figure 2; the ERAN inverts polarity at centrotemporal sites), supporting the finding that the ERAN is generated in the frontal cortex (Maess et al., 2001). Third, the ERAN elicited in the present experiment cannot be a frequency MMN (cf. Figure 1), but could only be an MMN elicited by the abstract feature "harmonically related versus harmonically unrelated." However, the abstract-feature MMN does not show a polarity inversion at mastoidal sites (with nose reference; c.f. Paavilainen, Jaramillo, \& Näätänen, 1998; Koelsch, Gunter, et al., 2001), whereas the ERAN distinctly does. Hence, the ERAN might be regarded as a special kind of abstract-feature MMN, namely an abstract-feature MMN with polarity inversal elicited by music-specific (e.g., "music-syntactic") incongruities. For convenience, we prefer the term ERAN.

\section{ERAN and ELAN}

Interestingly, the ERAN resembles the early left anterior negativity, or ELAN (e.g., Friederici, 1995; Hahne \& Friederici, 1999), though with a different scalp distribution: both components are widely distributed over the scalp, but the ELAN with a left- and the ERAN with a right-hemispheric weighting. The ELAN is an ERP component elicited by syntactic incongruities in auditory language experiments, and may be taken to reflect the processing of syntactic relations within a sentence. Analogously to the ELAN, the ERAN is elicited by harmonic incongruities and seems to reflect, at least partly, the processing of harmonic relations within a sequence of musical events. Moreover, the ELAN seems to have, at least partly, the same neuronal generators as the ERAN: both components receive contributions from virtually the same brain region in the lower part of BA 44 (Friederici et al., 2000; Maess et al., 2001).
However, it is suggested here that the present data strongly support the hypothesis that the neural generators of ELAN, ERAN, RATN, and MMN are part of a highly adaptive, peri-sylvian system of auditory information processing, comprising the processing of single tones (Näätänen, 1992; Schroger, 1998), acoustic patterns (Schroger, 1994), phonemes (Näätänen et al., 1997), tonal music (Koelsch, Gunter, et al., 2000), and speech (Friederici, 1998).

Independent of similarities and differences between ERAN, N1, MMN, RATN, and ELAN, the ERAN could only be elicited (and modulated in amplitude) by the application of (implicit) knowledge about the principles of harmonic distance and relatedness inherent in the major-minor tonal system. In this respect, the brain responses of participants may be regarded as musical; participants must have "understood" the music; otherwise the brain could not have been able to differentiate between in-key and out-of-key (Neapolitan) chords. Because this differentiation was present (as indexed by the ERAN) even under ignore conditions, the present results demonstrate a preattentive musicality of the human brain.

In summary, the present study demonstrates that chords that are from a music-theoretical perspective not compatible with an established musical context, and thus from a music-psychological perspective unexpected, elicit distinct early and late brain responses in nonmusicians, namely an ERAN and an N5. Results indicate that both ERAN and N5 can be elicited preattentively, that is, even when the musical stimulus is ignored. The amplitudes of these responses differ as a function of expectancies induced by a preceding musical context. Results thus provide evidence for a highly differentiated preattentive musicality of the human brain.

\section{REFERENCES}

Alain, C., Woods, D. L., \& Knight, R. T. (1998). A distributed cortical network for auditory sensory memory in humans. Brain Research, 812, 23-37.

Bharucha, J., \& Krumhansl, C. (1983). The representation of harmonic structure in music: Hierarchies of stability as a function of context. Cognition, 13, 63-102.

Bharucha, J., \& Stoeckig, K. (1986). Reaction time and musical expectancy: Priming of chords. Journal of Experimental Psychology: Human Perception and Performance, 12, 403-410.

Bharucha, J., \& Stoeckig, K. (1987). Priming of chords: Spreading activation or overlapping frequency spectra? Perception \& Psychophysics, $41,519-524$.

Bigand, E., \& Pineau, M. (1997). Global context effects on musical expectancy. Perception and Psychophysics, 59, 1098-1107.

Dapretto, M., \& Bookheimer, S.Y. (1999). Form and content: Dissociating syntax and semantics in sentence comprehension. Neuron, 24, 427-432.

Friederici, A. D. (1995). The time course of syntactic activation during language processing: A model based on neuropsychological and neurophysiological data. Brain and Language, 50, 259-281.

Friederici, A. D. (ed.) (1998). Language comprehension: A Biological Perspective. Berlin, New York: Springer.

Friederici, A. D., Wang, Y., Herrmann, C. S., Maess, B., \& Oertel, U. (2000). Localizing of early syntactic processes in frontal and temporal cortical areas: A MEG STUDY. Human Brain Mapping, 11, 1-11.

Giard, M. H., Perrin, F., Pernier, J., \& Bouchet, P. (1990). Brain generators implicated in the processing of auditory stimulus deviance: A topographic ERP-study. Psychophysiology, 27, 627-640.

Hahne, A., \& Friederici, A. D. (1999). Electrophysiological evidence for two steps in syntactic analysis: Early automatic and late controlled processes. Journal of Cognitive Neuroscience, 11, 194-205.

Hindemith, P. (1940). Unterweisung im Tonsatz, 1. Theoretischer Teil. Mainz, Germany: Schott.
Just, M. A., Carpenter, P. A., Keller, T. A., Eddy, W. F., \& Thulborn, K. R. (1996). Brain activation modulated by sentence comprehension. Science, 274, 114-116.

Koelsch, S., Gunter, T. C., Friederici, A. D., \& Schröger, E. (2000). Brain indices of music processing: 'Non-musicians' are musical. Journal of Cognitive Neuroscience, 12, 520-541.

Koelsch, S., Gunter, T. C., Schroger, E., Tervaniemi, M., Sammler, D., \& Friederici, A. D. (2001). Differentiating ERAN and MMN: An ERP study. NeuroReport, 12, 1385-1389.

Koelsch, S., Maess, B., \& Friederici, A. D. (2000). Musical syntax is processed in the area of Broca: An MEG study. Neuroimage, 11, S56.

Krumhans1, C. L., \& Kessler, E. J. (1982). Tracing the dynamic changes in perceived tonal organization in a spatial representation of musical keys. Psychological Review, 89, 334-368.

Kutas, M., \& Hillyard, S. A. (1980). Reading senseless sentences: Brain potentials reflect semantic incongruity. Science, 207, 203-205.

Maess, B., Koelsch, S., Gunter, T. C., \& Friederici, A. D. (2001). Musical syntax is processed in the area of Broca: An MEG study. Nature Neuroscience, 4, 540-545.

Meyer, M., Friederici, A. D., von Cramon, D. Y. (2000). Neurocognition of auditory sentence comprehension: Event related fMRI reveals sensitivity to syntactic violations and task demands. Cognitive Brain Research, 9, 19-33.

Näätänen, R. (1992). Attention and brain function. Hillsdale, NJ: Erlbaum.

Näätänen, R., Lehtokoski, A., Lennes, M., Cheour, M., Huotilainen, M., Iivonen, A., Vainio, M., Alku, P., Ilmoniemi, R. J., Luuk, A., Allik, J., Sinkkonen, J., \& Alho, K. (1997). Language-specific phoneme representations revealed by magnetic brain responses. Nature, 385, 432-434.

Näätänen, R., \& Picton, T. (1987). The N1 wave of the human electric and magnetic response to sound: A review and an analysis of the component structure. Psychophysiology, 24, 375-425.

Opitz, B., Mecklinger, A., von Cramon, D. Y., Kruggel, F. (1999). Com- 
bining electrophysiological and hemodynamic measures of the auditory oddball. Psychophysiology, 36, 142-147.

Paavilainen, P., Jaramillo, M., \& Näätänen, R. (1998). Binaural information can converge in abstract memory traces. Psychophysiology, 35, $483-487$.

Patel, A. D., Gibson, E., Ratner, J., Besson, M., \& Holcomb, P. J. (1998). Processing syntactic relations in language and music: An event-related potential study. Journal of Cognitive Neuroscience, 10, 717-733.

Pritchard, W. S. (1981). Psychophysiology of P300: A review. Psychological Bulletin, 89, 506-540.

Schönberg, A. (1969). Structural functions of harmony. New York: Norton.
Schroger, E. (1994). An event-related potential study on sensory representations of unfamiliar tonal patterns. Psychophysiology, 31, 175-181.

Schroger, E. (1998). Measurement and interpretation of the mismatch negativity (MMN). Behavior Research Methods, Instruments, \& Computers, 30, 131-145.

Swain, J. (1997). Musical languages. New York: Norton.

(Received February 3, 2000; Accepted July 9, 2001) 